\title{
Representasi Femininitas Pada Tokoh Juno dalam Film "Kucumbu Tubuh Indahku" (Analisis Semiotika Roland Barthes)
}

\author{
Theo Triansa Wijaya, Gregorius Genep Sukendro \\ theo.wijaya123@gmail.com,geneps@fikom.untar.ac.id \\ Fakultas Ilmu Komunikasi Universitas Tarumanegara
}

\begin{abstract}
Film is one of the most influential and massive mass communication media. The film "Kucumbu Tubuh Indahku" is one of the films that has this influence. This film tells the story of the life journey of a professional dancer and choreographer in Indonesia, Rianto. In this film, Rianto is told as Juno, an orphaned boy who has a sad and violent life journey, so as to melt the feminine and masculine characters that exist in his body. This research is a qualitative descriptive study with a semiotic approach, one of which is Roland Barthes' semiotics. The purpose of this research is to find out and show how and what are the signs, meanings of the results of the representation of femininity in the character Juno in the film "Kucumbu Tubuh Indahku". There are several theories that the author uses in this research, namely, the theory of film as mass communication, mass media, representation, Roland Barthes' semiotics, and Simone de Beauvoir's main theory of femininity. Based on the results of the analysis and findings made by the author about the representation of femininity in the character Juno in the film "Kucumbu Body Indahku". Juno's character can be said to be a man who tends to be feminine and less masculine, according to the description of Simone de Beauvoir's femininity characteristics, namely, cowardice, caring, emotional, multitasking, kind, patient, obedient, loves beauty and shy. But that doesn't matter, because these characters tend to be positive.
\end{abstract}

Keywords: feminity, film, Roland Barthes, semiotic

\begin{abstract}
Abstrak
Film merupakan salah satu media komunikasi massa yang paling berpengaruh dan massif. Film "Kucumbu Tubuh Indahku" menceritakan alur perjalanan hidup seorang penari dan koreografer profesional di Indonesia, Rianto. Dalam film ini, Rianto diceritakan sebagai Juno, seorang bocah yatim piatu yang memiliki perjalanan hidup yang pilu dan penuh kekerasan, sehingga terjadinya peleburan karakter feminin dan maskulin yang ada pada tubuhnya. Penelitian ini merupakan penelitian kualitatif deskriptif dengan pendekatan semiotika Roland Barthes. Tujuan penelitian ini untuk mengetahui dan memperlihatkan bagaimana dan apa saja tanda-tanda, makna-makna dari hasil representasi femininitas Simone de Beauvoir pada tokoh Juno dalam film "Kucumbu Tubuh Indahku". Peneliti mengkaji melalui konsep film sebagai komunikasi massa, media massa, representasi, semiotika Roland Barthes, dan teori utama femininitas Simone de Beauvoir. Berdasarkan hasil analisis dan temuan yang penulis lakukan tentang representasi femininitas pada tokoh Juno dalam film "Kucumbu Tubuh Indahku". Tokoh Juno dapat dikatakan sebagai laki-laki yang cenderung feminin dan kurang maskulin. sesuai dengan penjabaran karakteristik femininitas Simone de Beauvoir yaitu, penakut, peduli, lemah, emosional, multitasking, baik, sabar, taat, menyukai keindahan dan pemalu. Tetapi hal itu tidak menjadi masalah, karena karakter tersebut cenderung positif.
\end{abstract}

Kata Kunci: feminitas, film, Roland Barthes, semiotik 


\section{Pendahuluan}

Film menurut (Effendy, 1986:134) adalah sebuah pesan yang disampaikan secara audio visual, yang nantinya pesan tersebut akan diterima secara massal, baik secara kelompok maupun individu, dan memiliki pengaruh yang sangat massif. Karena menggunakan audio dan visual, film mampu bercerita banyak dan menyampaikan berbagai pesan hanya dalam waktu yang singkat. Selain itu karena menggunakan audio dan visual yang hidup, dengan sebuah film, dapat membuat audiens merasa seakan-akan dapat menembus ruang dan waktu, dan masuk kedalam kehidupan di cerita tersebut. Film-film yang ada di Indonesia yang mengangkat tema besar tentang gender atau LGBT. Indonesia sendiri sebagai negara yang masih mengacu pada budaya timur, negara dengan permasalahan gender yang cukup rumit, dengan akulturasi budaya yang ada di daerah Indonesia sendiri, menjadikan masalah gender dan LGBT sangatlah sensitif, dan salah satu film Indonesia yang mengangkat sebuah kebudayaan, gender dan LGBT adalah "Kucumbu Tubuh Indahku".

Film "Kucumbu Tubuh Indahku" merupakan sebuah film yang ditulis sekaligus disutradarai oleh Garin Nugroho, yang menceritakan alur perjalanan hidup seorang bocah bernama Juno yang tinggal dan hidup di sebuah desa penari Lengger. Menuju kedewasaannya, Juno melewati banyak hal-hal yang tak terduga, yang pada akhirnya Juno diceritakan menjadi sebuah gemblak seorang warok dalam tradisi klasik penari Reog. Film ini terinspirasi dari kehidupan salah satu penari Lengger asal Banyumas, Jawa Tengah yaitu Rianto. Rianto sendiri pun ikut turut serta berperan dalam film ini sebagai Juno dewasa dan hanya muncul dalam beberapa adegan monolog.

Peleburan femininitas dan maskulinitas dalam film ini membuat banyak orang bertanya-tanya bagaimana hal tersebut dapat terbentuk, aspek gender seperti apa yang seharusnya dimiliki Juno, masih banyak orang-orang yang belum mampu memahami budaya-budaya yang ada di dalam diri seseorang, masih banyak orang yang mempermasalahkan gender maskulinitas atau femininitas seseorang, bahwa maskulinitas dan femininitas itu harus ada di setiap dalam diri laki-laki maupun perempuan, laki-laki harus maskulin dan perempuan harus feminin. Maka dari itu, Juno di dalam film "Kucumbu Tubuh Indahku" melewati berbagai macam hal dan peristiwa untuk mencapai peleburan tersebut. Berbagai hal dan peristiwa tersebut penulis analisis melalui tanda-tanda yang ada menggunakan analisis semiotika Roland Barthes.

Konsep pemikiran Barthes terhadap semiotik terkenal dengan konsep mythologies atau mitos. "Sebagai penerus dari pemikiran Saussure, Roland Barthes menekankan interaksi antara teks dengan pengalaman personal dan cultural penggunanya, interaksi antara konvensi dalam teks dengan konvensi yang dialami dan diharapkan oleh penggunanya" (Kriyantono, 2007: 268). Konsep pemikiran Barthes yang operasional ini dikenal dengan Tatanan Pertandaan (Order of Signification). Secara sederhana, kajian semiotik Barthes bisa dijabarkan sebagai berikut (Prasetya, 2019: 14): 1) Denotasi, makna yang sesungguhnya; 2) Konotasi, makna yang muncul karena adanya konstruksi budaya.

Media film bukanlah hal baru yang pernah kita dengar dan tidak akan pernah lepas seiring dengan perkembangan jaman dan teknologi. Menurut Danesi, film merupakan teks yang memuat serangkaian citra fotografi yang mengakibatkan adanya ilusi gerak dan tindakan dalam kehidupan nyata (Yustiana dan Junaedi, 2019). Tentu saja dalam hal ini dapat mempengaruhi pikiran khalayak dan 
Theo Triansa Wijaya, Gregorius Genep Sukendro: Representasi Feminitas Pada Tokoh Juno dalam Film "Kucumbu Tubuh Indahku” (Analisis Semiotika Roland Barthes)

memberikan efek stimulus dengan segala estetika yang ditampilkan dalam sebuah karya kreatif. McQuail mengemukakan bahwa film berperan sebagai sarana baru yang digunakan untuk menyebarkan hiburan yang sudah menjadi kebiasaan terdahulu, serta menyajikan cerita, peristiwa, musik, drama, lawak, dan sajian teknis lainnya kepada masyarakat umum (Prasetya, 2019). Tujuan khalayak menonton film tentunya adalah untuk mendapatkan hiburan usai bekerja, beraktivitas atau hanya sekadar untuk mengisi waktu luang. Akan tetapi dalam film dapat terkandung fungsi informatif, maupun edukatif, bahkan persuasif (Ardiyanto, dalam Prasetya, 2019).

Femininitas menurut Simone de Beauvoir (Widyastuti, 2018:20) banyak sekali karakter yang menunjukkan femininitas, penulis mengerucutkannya menjadi beberapa saja yaitu: takut, peduli (simpati), lemah, emosional, multitasking, baik, sabra, taat, menyukai keindahan, dan pemalu.

Penelitian ini bertujuan mengetahui dan memperlihatkan bagaimana dan apa saja tanda-tanda, makna-makna dari hasil representasi femininitas Simone de Beauvoir dari tokoh Juno dalam film "Kucumbu Tubuh Indahku. Penelitian serupa juga pernah dilakukan dengan menggunakan teori gender dan analisis semiotika dengan judul "Representasi Maskulinitas Pada Tokoh Juno Dalam Film "Kucumbu Tubuh Indahku" yang terbit di Jurnal Syntax Transformation Universitas Pembangunan Nasional "Veteran" Jawa Timur pada tanggal 8 Oktober 2020. Penelitian tersebut fokus pada representasi maskulinitas pada tokoh Juno dan menggunakan analisis semiotika John Fiske, sedangkan dalam penelitian ini, penulis mengangkat representasi femininitas yang ada pada tokoh Juno, dengan bantuan metode analisis semiotika Roland Barthes di mana pada pencarian makna denotatif, konotatif dan mitos.

\section{Metode Penelitian}

Penelitian ini menggunakan metode penelitian kualitatif deskriptif, mendefinisikan metodologi kualitatif sebagai prosedur penelitian yang menghasilkan data deskriptif berupa kata-kata tertulis atau lisan dari orang-orang dan perilaku yang dapat diamati. Sejalan dengan definisi tersebut, Kirk dan Miller mendefinisikan bahwa penelitian kualitatif adalah tradisi tertentu dalam ilmu pengetahuan sosial yang secara fundamental bergantung dari pengamatan pada manusia baik dalam kawasannya maupun dalam peristilahannya (Moleong, 2017:4).

Metode penelitian yang digunakan pada penelitian ini adalah dengan metode analisis semiotika Roland Barthes, yang mengutamakan memaknakan tanda-tanda berupa denotasi, konotasi dan mitos. Selain itu peneliti menjabarkan sepuluh karakteristik femininitas dengan femininitas Simone de Beauvoir.

Subjek penelitian adalah film "Kucumbu Tubuh Indahku", sedangkan objek penelitian adalah tanda-tanda representasi femininitas Simone de Beauvoir yang ada pada tokoh Juno. Proses pengumpulan data adalah dengan cara observasi non partisipan, dengan mengamati film "Kucumbu Tubuh Indahku" secara berulangulang untuk mencari tanda-tanda representasi yang dibutuhkan, studi pustaka, dan dokumentasi, dengan mengambil tangkapan layar adegan-adegan yang merepresentasikan femininitas Simone de Beauvoir pada tokoh Juno.

Teknik keabsahan data yang digunakan dalam penelitian ini adalah dengan menggunakan teknik kepastian uraian rinci, yaitu dengan maksud bahwa penelitian ini dilakukan dari sudut pandang penulis sendiri sebagai peneliti, sehingga belum dapat dipastikan hasil penelitian ini hal yang objektif atau tidak bergantung pada 
pandangan orang lainnya. Dan dibantu dengan teknik uraian rinci, yang menuntut penulis untuk membuat uraian serinci mungkin dan seteliti mungkin, agar menghasilkan laporan penelitian yang memuaskan dan tentu saja menghasilkan objektivitas dan konteks dari penelitian itu sendiri.

\section{Hasil Temuan dan Diskusi}

Pada bagian ini penulis memaparkan hasil temuan analisis dan pembahasan berupa potongan-potongan adegan yang menurut penulis merujuk pada representasi femininitas Simone de Beauvoir pada tokoh Juno dalam film "Kucumbu Tubuh Indahku"

1. Scene 1 Juno Membuka Bajunya dan Membasuh Tubuh Petinju (00:45:21 - 00:45:36), pada adegan tersebut Juno berbuat baik dan memberikan perhatian lebih kepada si petinju, dengan cara melepas baju yang ia gunakan dan menggunakan baju itu untuk mengeringkan tubuh si petinju yang basah karena si petinju diceritakan habis mandi, agar baju pengantin yang akan dikenakan nanti tidak basah. Kebanyakan perempuan selalu memberikan kebaikan dan perhatian yang lebih untuk temannya atau pasangannya, karena perempuan memiliki hati dan perasaan yang lebih lemah dibanding laki-laki. Pada adegan ini, tokoh Juno mampu merepresentasikan femininitas baik Simone de Beauvoir.

2. Scene 2 Juno Memberikan Contoh Menggunakan Kebaya (00:48:22). pada adegan ini, si petinju meminta tolong kepada Juno untuk mencontohkan bagaimana cara memakai kebaya, agar si petinju dapat mempraktekkannya pada istrinya nanti. Juno pun dengan senang hati mengiyakan permintaan tolong si petinju. Juno secara langsung memakai kebaya tersebut melalui gerakan tubuh nya yang lemah lembut. Seperti yang kita tahu sendiri, gerakan lemah lembut merupakan hal yang terbiasa ada pada karakter perempuan, perempuan memiliki pikiran bahwa semua hal yang dikerjakan harus dengan hati-hati, melalui hati-hati tersebut menjadi sebuah gerakan lemah lembut. Selain itu, Kebaya juga merupakan sebuah pakaian tradisional yang dikenakan perempuan, dan biasanya digunakan dalam hal perayaan-perayaan yang penting. Hingga saat ini penggunaan kebaya semakin populer di kalangan perempuan Indonesia, sehingga dapat dikenakan dari acara formal seperti pernikahan, rekan bisnis, acara tradisional dan non formal seperti acara perayaan kelulusan sekolah seperti wisuda.

3. Scene 3 Juno Menari Diatas Ring Tinju (00:50:50), pada adegan ini, si petinju meminta Juno untuk menutup matanya, karena si petinju ingin melatih instingnya sebagai petinju dan hanya mengandalkan indra penciumannya. Setelah mata si petinju tertutup, Juno pun langsung menggerakan tubuhnya yang lentik dan gemulai itu, Juno menari dengan indahnya di atas ring, selagi petinju berusaha mencari Juno. Juno menari dengan berani dan totalitas, tanpa merasa adanya beban, karena ia merasa tidak ada yang perlu dikhawatirkan, karena tidak ada siapapun yang melihat dia menari diatas ring tersebut. Adegan tersebut merupakan representasi femininitas pemalu yang dijabarkan oleh Simone de Beauvoir. 
4. Scene 4 Juno Mendengarkan Curhatan Si Petinju (00:51:48), pada adegan ini, Juno tampak santai tanpa merasa ada beban sedikitpun ia memotong buah pepaya sambil mendengarkan kisah masa lalu si petinju yang pilu, Juno memang diam saja dan tidak memberikan tanggapan apapun, tapi Juno langsung meresapi curahan hati si petinju dan menenangkannya dengan memberikan potongan buah pepaya yang telah ia potong selama ia mendengarkan curahan hati si petinju. Adegan ini merepresentasikan tokoh Juno yang multitasking sesuai dengan penjabaran karakteristik femininitas Simone de Beauvoir.

5. Scene 5 Juno Diberikan Bunga Yang Menyerupai Aksesoris (00:55:07 00:55:21), pada adegan ini, Juno terlihat sangat bahagia, hanya bermodalkan hadiah kecil nan sederhana, yaitu berupa aksesoris cincin dan anting yang terbuat dari bunga. Mungkin yang dipikirkan Juno bukanlah anting dan cincin yang terbuat dari bunga tersebut, melainkan bahwa hal tersebut diberikan oleh orang yang menurutnya spesial, yaitu si petinju, sehingga membuat Juno menutup mukanya yang menggambarkan rasa malu, Juno pun tak hentihentinya tersenyum. Adegan ini merepresentasikan femininitas emosional Simone de Beauvoir pada tokoh Juno.

6. Scene 6 Juno Latihan Menari Di Sanggar Lengger Lanang (1:09:29), pada adegan ini, Juno berlatih sendirian, sedangkan teman-temannya asik sendiri. Juno tidak peduli, ia hanya fokus pada gerakan tubuhnya agar menghasilkan gerakan tari yang indah. Juno berlatih sebagai rasa tanggung jawabnya selaku anggota baru pada sanggar tersebut, dan ia berpikir untuk tampil maksimal demi teman-temannya yang sudah mempercayakan ia bergabung dengan sanggar tersebut. Adegan ini berhasil merepresentasikan karakter femininitas taat Simone de Beauvoir pada tokoh Juno.

7. Scene 7 Juno Merias Wajahnya Dengan Apik (1:18:07 - 1:19:07), pada adegan ini, Juno dengan ahlinya merias dirinya sendiri menggunakan jarijarinya yang lentik, dalam hal ini, Juno sedang merias dengan maksud untuk bersiap-siap dalam penyelenggaraan pentas seni tari yang akan dimainkan oleh Juno dan teman-teman sanggarnya. Tetapi dalam hal merias wajah, Juno tampak sangat menikmati hal itu bagaikan perempuan yang sedang merias wajahnya sendiri, dan dapat diingatkan bahwa tokoh Juno adalah laki-laki. Adegan ini dapat merepresentasikan femininitas Simone de Beauvoir akan karakter feminis yang menyukai keindahan, terutama dalam hal penampilan.

8. Scene 8 Juno Menyelimuti Warok Yang Sedang Tertidur (1:24:17), pada adegan ini, Juno memberikan perhatian dan kepedulian kepada warok. Ia melihat warok yang sedang tertidur pulas tanpa mengenakan sehelai kain di tubuhnya, Juno pun langsung secara cepat mengambil kain, dan dijadikan selimut untuk menutupi tubuh warok yang sedang tertidur, agar tetap hangat dan dapat tertidur dengan pulas. Rasa perhatian dan peduli Juno pada warok merupakan perhatian yang spesial, Juno memberikan perhatian itu seperti memberikan perhatian kepada pasangannya, oleh karena itu Juno sukses merepresentasikan femininitas Simone de Beauvoir sifat peduli (empati) yang cenderung ada pada sifat perempuan, dan bukan laki-laki.

9. Scene 9 Juno Memasak Untuk Warok (01:24:37 - 01:24:47), memasak merupakan hal yang mudah baginya, memasak sudah menjadi aktivitas yang biasa ia lakukan sedari kecil. Pada adegan ini, tokoh Juno merepresentasikan 
femininitas kepedulian Simone de Beauvoir berbentuk kegiatan domestik yaitu memasak.

10. Scene 10 Juno Membatik (1:28:37), pada adegan ini, melalui perjalanan dan juga pengalaman hidupnya di bidang kesenian, dari menjahit, mengukur tubuh tanpa meteran, dan bahkan menari, Juno memiliki bakat untuk membatik, tentu saja, seperti yang kita tahu, pekerjaan membatik sangatlah lekat dengan perempuan, karena dikatakan perempuan memiliki tingkat kesabaran dan konsentrasi yang lebih tinggi dibanding laki-laki, tetapi pada adegan ini, Juno berhasil menunjukkan sebagai laki-laki yang dapat juga membatik, sehingga hal tersebut merepresentasikan femininitas sabar dan taat Simone de Beauvoir.

11. Scene 11 Juno Melihat Warok Bertarung (1:34:22 - 1:34:28), pada adegan ini, Juno menyaksikan pertarungan hidup dan mati warok nya melawan warok lain yang berusaha merebut Juno dari warok-nya yang sekarang. Juno yang tahu dan melihat pertarungan itu secara langsung, membuat ia ketakutan, gelisah dan khawatir. Pertarungan warok untuk mempertahankan gemblak-nya dari warok lain yang ingin merebutnya, merupakan hal yang umum dalam seni Tari Reog dalam budaya masyarakat Jawa. Karena gemblak adalah hal yang sangat berharga bagi warok, bahkan warok rela mati demi mempertahankan gemblak-nya. Maka dari itu adegan diatas dapat merepresentasikan tokoh Juno sebagai femininitas takut dan gelisah Simone de Beauvoir.

12. Scene 12 Juno Berkonflik Dengan Warok (1:34:56 - 01:35:07), pada adegan ini, Juno tampak terlihat sangat emosional, Juno marah terhadap hidupnya, ia tidak menyalahkan warok nya sama sekali, tetapi terhadap kehidupannya. Juno sedari kecil sudah melihat darah dan selalu berurusan dengan darah, hidupnya hanya ada dia dan darah. Di saat ia menemukan titik tenang dalam hidupnya, tidak butuh waktu lama hal tersebut akan kembali menjadi darah. Diawali oleh Juno yang melihat salah satu anggota Lengger dibunuh secara kejam oleh guru Lengger-nya, sang ayah yang dibawa pergi paksa, guru tari perempuan yang menjadi korban misogini, seorang petinju yang ia cintai berakhir di rumah sakit, dan yang terakhir seorang warok lain yang menantang warok-nya atas "kepemilikan" Juno sebagai gemblak. Dengan adanya sifat emosional mendalam seperti yang ditunjukkan Juno, hal tersebut merepresentasikan femininitas emosional Simone de Beauvoir.

\section{Simpulan}

Tokoh Juno dapat dengan baik merepresentasikan femininitas Simone de Beauvoir dalam Film "Kucumbu Tubuh Indahku". Karakter tersebut berupa, takut yang direpresentasikan dalam adegan 11, peduli yang direpresentasikan dalam adegan 8 dan 9, emosional yang direpresentasikan dalam adegan 5 dan 12, multitasking yang direpresentasikan dalam adegan 4, baik yang direpresentasikan dalam adegan 1 dan 2, sabar yang direpresentasikan dalam adegan 10, taat yang direpresentasikan dalam adegan 6, menyukai keindahan yang direpresentasikan dalam adegan 7 dan 2, lalu yang terakhir pemalu yang direpresentasikan dalam adegan 3. Penulis tidak dapat menemukan representasi femininitas lemah Simone de Beauvoir, yang menandakan tokoh Juno sebagai laki-laki cenderung feminin dan 
Theo Triansa Wijaya, Gregorius Genep Sukendro: Representasi Feminitas Pada Tokoh Juno dalam Film "Kucumbu Tubuh Indahku" (Analisis Semiotika Roland Barthes)

kurang maskulin tetapi memiliki karakter femininitas Simone de Beauvoir yang positif.

\section{Ucapan Terima Kasih}

Penulis mengucapkan terima kasih kepada seluruh pihak yang telah membantu penulis dalam menyelesaikan penelitian ini, dosen pembimbing, dan Fakultas Ilmu Komunikasi Universitas Tarumanagara.

\section{Daftar Pustaka}

Effendy, Onong Uchjana. (1986). Dimensi Dimensi Komunikasi. Bandung: Alumni. Moleong, Lexy J. (2017). Metodologi Penelitian Kualitatif. Bandung: Remaja Rosdakarya.

Prasetya, Arif Budi. (2019). Analisis Semiotika Film Dan Komunikasi. Malang: Intrans Publishing.

Widyastuti, Diah Kusuma. (2018). Representasi Feminitas Pada Karakter Affandi Dalam Film 3 Dara. http://repository.isi-ska.ac.id/2713/, diunduh pada tanggal 8 Desember 2020.

Yustiana, Melia \& Ahmad Junaedi. (2019). Representasi Feminisme dalam Film Marlina si Pembunuh dalam Empat Babak (Analisis Semiotika Roland Barthes). $\quad 3(1), \quad 118 \quad$ - 125. https://journal.untar.ac.id/index.php/koneksi/article/view/6154/4214, diunduh pada tanggal 6 Oktober 2020. 